\title{
Assessing childhood maltreatment on the population level in Germany: findings and methodological challenges
}

\author{
Heide Glaesmer
}

\begin{abstract}
Childhood maltreatment (CM) is both prevalent and consequential. Unfortunately little is known about the true prevalence of CM in the general population in Germany. The differences between findings from top down vs. bottom up approaches and the problem of the dark field of CM is discussed. Different assessment methods like trauma lists, the Childhood Trauma Questionnaire (CTQ) and the Childhood Trauma Screener (CTS) are described and the respective findings about the prevalence of $\mathrm{CM}$ in the adult German general population are discussed. With the example of childhood sexual abuse (SA) the challenges of quantification of CM is shown up. For instance, even if all the prevalence findings were based on methodologically sound large-scale studies, it could only be assumed that the retrospectively investigated prevalence of SA in the German general population ranges between 1.0 and $12.6 \%$ in different studies. These findings provide an insight into the complexity of the quantification of the true prevalence of $\mathrm{CM}$ on the population level. Hopefully it reminds the readers of handling prevalence rates of CM carefully and to dip into the methodology of the studies before citing the respective prevalence of CM.
\end{abstract}

Keywords: Childhood maltreatment, CTQ, General population, Childhood, Abuse, Neglect, Germany

\section{Background}

Childhood maltreatment (CM) is defined as "any act of commission or omission by a parent or other caregiver that results in harm, potential harm, or threat of harm to a child. Harm does not need to be intended" [1]. Hence, $\mathrm{CM}$ includes physical, sexual and emotional abuse as well as physical and emotional neglect (see Table 1 in [1]). CM is both prevalent and consequential and remains a major public health and social welfare problem in high income countries [1-3]. According to Gilbert et al. [1,3] about $4-16 \%$ of children are physically abused and around $10 \%$ of children are neglected or psychologically abused [1]. CM substantially contributes to child mortality and morbidity. The long-lasting effects on mental and physical health, substance abuse, risky sexual behaviour, and criminal behaviour persist into adulthood $[1,2,4]$. Due to its prevalence as well as its complex and cumulative

*Correspondence: Heide.Glaesmer@medizin.uni-leipzig.de Department of Medical Psychology and Medical Sociology, University of Leipzig, Philipp-Rosenthal-Str. 55, 04103 Leipzig, Germany effects on the developing brain, mind and body CM is perhaps one of the most important factors to assess in a variety of contexts [5]. Additionally detection and reporting of CM matters to promote child safety and health and to inform professionals in health care, in educational and law system as well as policy makers [3]. Drawing on the example of the assessment of $\mathrm{CM}$ on the population level in Germany and especially of sexual abuse (SA), the challenges and pitfalls of the assessment of $\mathrm{CM}$, will be discussed in the following.

\section{Assessment of CM}

Essentially, there are two approaches of quantification of $\mathrm{CM}$ on the population level: a top down and a bottom up approach. While the top down approach uses official statistics from child protection agencies or reports to the police, the bottom up approach uses data from epidemiological studies in different populations like children of different ages, adolescents and adults. The prevalence of $\mathrm{CM}$ from a bottom up assessment is much higher than from top down sources. This provides strong evidence 
that a larger proportion of $\mathrm{CM}$ is not reported [3]. This underrecognized and underreported share of $\mathrm{CM}$ is called the "dark field of childhood maltreatment". To light this dark field is one of the major challenges. A combination of evidence from both approaches and all available sources seems promising for the estimation of the true prevalence of CM.

Several well-established instruments for the assessment of CM in clinical and epidemiological research are available to date. The spectrum ranges from self-report measures to (standardized) interviews, and from categorial (yes vs. no; e.g. list of traumatic events) to dimensional measures of CM. A recent systematic review gives an insight into the usually applied assessment methods in population surveys [6]. In large-scale epidemiological studies economic assessment tools are needed to support feasibility of the study protocols. Thus complex and comprehensive measures are not always the usual assessment tools applied in population surveys [6].

The most economic assessment is the use of self-report lists of traumatic events, e.g. Traumalist of the M-CIDI [7]. These lists usually have a dichotomous format, hence the participants indicate whether they have experienced different kinds of traumatic events or not. This forthright way of assessment requires participants capable of memorizing and critically reflecting upon their experiences as well as a kind of precise phenomenological understanding of a specific traumatic event (e.g. what exactly means sexual abuse). Thus such lists might be suitable for the assessment of commonly defined traumatic events like car accident or natural disaster. However the assessment of emotional neglect or sexual abuse might not work well with a traumalist. Moreover this specific type of list does not allow assessing frequency, duration and severity of the respective experiences and requires self-identification of the respondents.

The Childhood Trauma Questionnaire (CTQ) [8] is an internationally established tool for the retrospective assessment of $\mathrm{CM}$ in adolescent and adult populations [9]. The original version of the CTQ was developed from a 70-item questionnaire. In further studies the questionnaire was reduced to a 28 -item version using exploratory and confirmatory factor analyses. This 28 -item questionnaire is the most commonly used version applied in a vast number of studies in different languages and settings. Based on theoretical assumptions the CTQ consists of five subdimensions: physical abuse (PA; e.g. "...got hit so hard that I had to see a doctor or go to the hospital"), sexual abuse (SA, e.g. "...someone tried to touch me in a sexual way/made me touch him."), emotional abuse (EA, e.g. "...people in my family called me stupid, lazy or ugly."), physical neglect (PN, e.g. "...I knew there was someone to take care of me and protect me."), and emotional neglect (EN, e.g. “...someone in my family helped me feel important or special., reverse coded) with five items representing each subdimension with a fivepoint likert scale for each item $(1=$ "never" to $5=$ "very often"). The sum of the five items for each subscale ranges from 5 to 25 . According to the original manual the sumscores of the subscales are classified for severity on four levels [8]. A slightly different procedure of severity ratings was recommended by Walker et al. [10] with a dichotomous differentiation of CM. These cut-off criteria had been ascertained by relating CTQ subscale scores to ratings of expert blinds for the CTQ scores who administered detailed clinical interviews. Based on the fulfillment of consensus childhood abuse and neglect criteria, experts determined whether participants had a history of clinically significant abuse or neglect [10]. Table 1 gives an overview about both scorings. According to Walkers approach PA and PN include all cases from "slight to moderate" up to "extreme" CM, SA and EN include all cases from "moderate to severe" up to "extreme" CM. For EA the cut-off is in the middle of the "slight to moderate"-level.

There is mixed evidence about the dimensionality of the CTQ, with some indications that its structure may vary across different groups. Especially the psychometric properties of the PN subscale are subject to a critical debate $[8,11-14]$. The internal consistencies of the subscales lay between 0.62 and 0.96 [8]. As a measure of test-retest reliability at a median interval of 6 weeks, the intraclass coefficient were 0.77 for the CTQ as a whole and $0.58-0.81$ for the subscales [15]. The results of the CTQ show moderate correlations with those of semistructured interviews (from 0.43 for physical and emotional abuse to 0.57 for sexual abuse) [16]. Furthermore, the results of the CTQ show correlations with ratings by psychotherapists from 0.42 for physical neglect to 0.72 for sexual abuse [17].

Despite the fact that some evidence suggests moderate to good consistency of self-reports of maltreatment over time, the retrospective nature of the CTQ carries some risk of response bias that could possibly undermine the validity of this instrument. Hence, besides the 25 items representing five subscales of the CTQ another 3-item-response-bias scale called minimization-denial scale (MD) was included by the original authors. Unfortunately, the overwhelming majority of studies reporting CTQ data neither include information about MD items nor take these items into account for analyses and interpretation [18]. Thus little is known about this MD measure. Moreover, if response biases are common and consequential, current practices of minimizing the MD scale deserve revision. Thus, a recent re-analysis of data from 24 multinational samples with a total of 19,652 
Table 1 Classification of abuse and neglect along the sum scores of the subscales

\begin{tabular}{llllll}
\hline & \multicolumn{2}{l}{ Classification according to Bernstein [8] } & Classification according to Walker [10] \\
\cline { 2 - 5 } & None to minimal & Slight to moderate & Moderate to severe & Severe to extreme & \\
\hline Emotional abuse & $5-8$ & $9-12$ & $13-15$ & $16-25$ & $10-25$ \\
Physical abuse & $5-7$ & $8-9$ & $10-12$ & $13-25$ & $8-25$ \\
Sexual abuse & 5 & $6-7$ & $8-12$ & $13-25$ & $8-25$ \\
Emotional neglect & $5-9$ & $10-14$ & $15-17$ & $18-25$ & $15-25$ \\
Physical neglect & $5-7$ & $8-9$ & $10-12$ & $13-25$ & $8-25$ \\
\hline
\end{tabular}

participants was performed [19]. Overall, results of this analysis suggest that a minimizing response bias-as detected by the MD subscale-has a small but significant moderating effect on the discriminative validity of the CTQ. Researchers and clinicians should be cautioned about the widespread practice of using the CTQ without the MD scale, or collecting MD data but failing to control for its effects on outcomes or dependent variables [19].

To support the economic assessment CM a short screening instrument was developed based on the German version of the CTQ. The Childhood Trauma Screener (CTS) consists of 5 items (each item representing one subscale of the CTQ [20]. The correlations between the 5 items and the respective subscales of the CTQ range between $r=0.55$ and $r=0.87$. Internal consistency of the CTS was good $(\alpha=0.757)$ [20]. To support the application of the CTS for categorical diagnostics cut-offs of the different dimensions of CM have been defined based on two large-scale population studies in Germany [21]. A further investigation of psychometric properties of the CTS is necessary.

\section{CM on the population level in Germany}

The findings from several studies investigating $\mathrm{CM}$ on the population level in Germany are outlined and discussed below. Table 2 gives an overview about the core methodological characteristics of the different studies. Frequency and severity of CM in the adult German population was investigated using the CTQ in a populationbased representative study in 2010 [22]. The data have already been published. For more detailed information please refer to the original publications $[22,23]$. Table 3 gives an overview about the frequency of $\mathrm{CM}$ according to the four severity levels recommended by Bernstein [8, 23 ] and according to the dichotomous approach recommended by Walker $[10,22]$ from this study. The application of different cut-offs for the definition of caseness leads to different statements about the frequency of CM on the population level (Table 3).
The CTS as a short screening tool out of the CTQ was used in two samples to quantify the frequency of CM [21]. One study is a large-scale community sample (Study of Health in Pomerania) from northeastern Germany the other one is the population-based representative sample mentioned above (for more details see Table 2). The prevalences of CM from both studies are presented in Table 3. The results differ slightly in both samples. Currently it is impossible to determine whether this is attributable to the differences in both samples (population-based representative German sample vs. community sample from northeast of Germany, see Table 2) or to the psychometric problems of a short screener, such as the CTS. Further research is needed to verify the psychometric properties of the CTS.

Additionally, in 2005 and 2007 two population based representative surveys assessed the frequency of traumatic events in Germany, including childhood sexual abuse (up to the age of 14), using a traumalist [24, 25] (for more details concerning methodology see Table 2). The findings of both studies are comparable with a prevalence of childhood sexual abuse of $1.2 \%$ in the study of 2005 [25] and $1.0 \%$ in the study of 2007 [24].

\section{Conclusions}

The prevalence of CM in the general population in Germany assessed with a bottom up approach depends on the instrument used and the applied cut-off scores. The example of experiences of childhood sexual abuse in the German general population, illustrates what this means. Using a trauma list (with a dichotomous answer format) the prevalence of SA ranges between 1.0 and $1.2 \%$ [24, 25]. Using the CTQ as a dimensional self-report measure with five subscales, the prevalence of SA is 6.2 vs. $12.6 \%$ depending on the cut-off-score. Based on the CTS the prevalence of SA is 4.3 vs. $9.5 \%$ in two different samples (for details see Table 2). With this example of childhood sexual abuse the challenges of the quantification of CM is shown up. Even if all these prevalence data are based on methodologically sound large-scale studies, we can only say that the retrospectively investigated prevalence of SA 


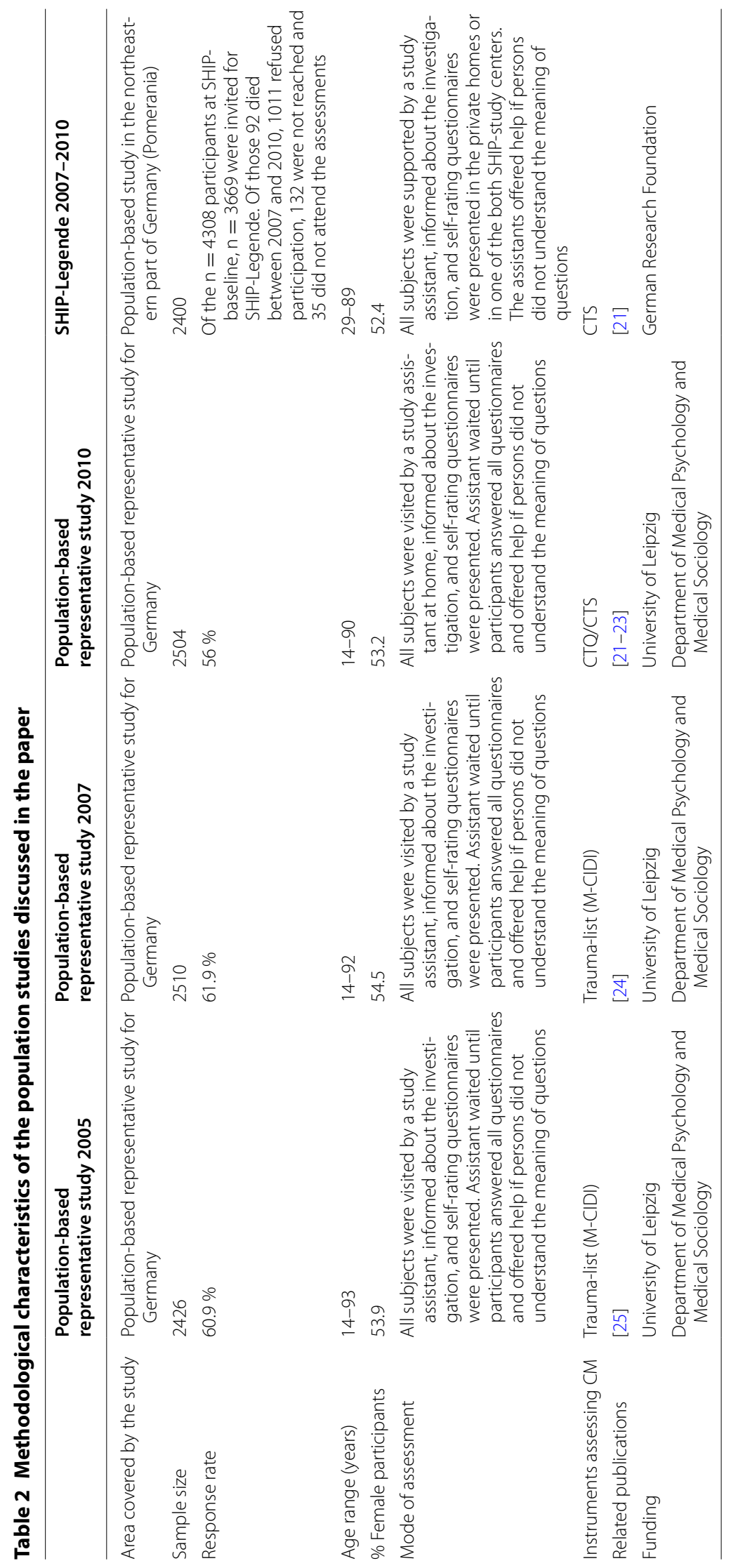


Table 3 Frequency and severity of CM in the German general population

\begin{tabular}{|c|c|c|c|c|c|c|c|c|c|c|c|c|c|c|}
\hline & \multicolumn{8}{|c|}{ CTQ_-classification according to Bernstein [8] } & \multirow{2}{*}{\multicolumn{2}{|c|}{$\begin{array}{l}\text { CTQ_classifica- } \\
\text { tion according } \\
\text { to Walker }[10]^{\mathrm{b}}\end{array}$}} & \multirow{2}{*}{\multicolumn{2}{|c|}{$\begin{array}{l}\text { CTS German } \\
\text { community } \\
\text { sample (SHIP } \\
\text { LEGENDE) }\end{array}$}} & \multirow{2}{*}{\multicolumn{2}{|c|}{$\begin{array}{l}\text { CTS Repre- } \\
\text { sentative } \\
\text { German } \\
\text { sample } \\
2010^{C}\end{array}$}} \\
\hline & \multicolumn{2}{|c|}{ None to minimal } & \multicolumn{2}{|c|}{$\begin{array}{l}\text { Slight to moder- } \\
\text { ate }\end{array}$} & \multicolumn{2}{|c|}{$\begin{array}{l}\text { Moderate } \\
\text { to severe }\end{array}$} & \multicolumn{2}{|c|}{$\begin{array}{l}\text { Severe } \\
\text { to extreme }\end{array}$} & & & & & & \\
\hline & $\mathrm{n}$ & $\%$ & $\mathrm{n}$ & $\%$ & $\mathrm{n}$ & $\%$ & $\mathrm{n}$ & $\%$ & $\mathrm{n}$ & $\%$ & $\mathrm{n}$ & $\%$ & $\mathrm{n}$ & $\%$ \\
\hline Emotional abuse & 2123 & 84.8 & 259 & 10.3 & 75 & 3.0 & 40 & 1.6 & 254 & 10.2 & 110 & 5.2 & 170 & 6.7 \\
\hline Physical abuse & 2198 & 87.8 & 162 & 6.5 & 70 & 2.8 & 69 & 2.7 & 301 & 12.0 & 99 & 4.7 & 132 & 5.3 \\
\hline Sexual abuse & 2186 & 87.3 & 158 & 6.3 & 109 & 4.3 & 47 & 1.9 & 156 & 6.2 & 92 & 4.3 & 172 & 6.9 \\
\hline Emotional neglect & 1259 & 50.3 & 888 & 35.5 & 184 & 7.3 & 164 & 6.5 & 348 & 13.9 & 214 & 10.1 & 167 & 6.7 \\
\hline Physical neglect & 1288 & 51.4 & 491 & 19.6 & 450 & 18.0 & 269 & 10.8 & 1210 & 48.4 & 226 & 10.6 & 364 & 14.7 \\
\hline
\end{tabular}

a Published data, for more details see [23]

b Published data, for more details see [22]

c Published data, for more details see [21]

in the German adult population ranges between 1.0 and $12.6 \%$.

There are several sources of error: (1) representativeness of the population under study; (2) recall bias, especially for retrospective measures like the CTQ; (3) the quality of the assessment instrument. The studies discussed above are large-scale population based samples which are methodically sound with respect to representativeness, sample size etc., Nevertheless they were assessing CM retrospectively and especially in the older age groups these studies refer to experiences decades ago. Thus a critical reflection about recall bias is important. From a psychometric or methodological perspective, dimensional measures with several items assessing every subdomain of $\mathrm{CM}$ including a rating of the frequency of the experiences (e.g. CTQ) seem to be more reliable measures than a dichotomous item on a trauma list. Hence, with the use of dimensional measures the question of the correct cut-off-score arises. The big question is: Can we recommend one cut-off-score for the CTQ, in different settings (clinical vs. general population), different cultural backgrounds or different age-groups? Even if this is not an easy to handle recommendation it seems worthwhile to discuss different cut-off-scores depending on the field of application (e.g. lower cut-offs for screening). Moreover, the length of an instrument and its operationalization is a very important topic and a possible source of error. For instance the CTQ-subscale PN includes one item "I didn't have enough to eat." This item is a possible source of error when applied in the German elderly who grew up in the postwar-period in Germany with very common experiences of shortages of food etc. in this time. Thus this item will lead to an overestimation of PN in this age group. Additionally, the items of the CTQ are more or less clear, e.g. "I got hit so hard by someone in my family that I had to see a doctor or go to the hospital." is operationalizing PA in a behavioural manner. On the other hand, an item like "I felt loved." assesses the feeling of being loved with some aspect of interpretation what that could mean and carries a margin for interpretation. Even though the problem of fixing the prevalence of $\mathrm{CM}$ in the general population in Germany is not resolved with all these studies, this compilation of data from Germany gives an insight in the complexity of the problem. Hopefully, it reminds the readers in handling prevalence information about $\mathrm{CM}$ with care and to dip into the methodology of the studies before citing prevalence rates of $\mathrm{CM}$.

\section{Abbreviations}

CM: childhood maltreatment; PN: physical neglect; EN: emotional neglect; PA: physical abuse; EA: emotional abuse; SA: sexual abuse; CTQ: Childhood Trauma Questionnaire; MD: minimization-denial scale; CTS: Childhood Trauma Screener; M-CIDI: Munich Composite International Diagnostic Interview.

\section{Authors' information}

Heide Glaesmer is a trained psychologist and psychotherapist (CBT). She is acting as the vice head of the Department of Medical Psychology and Medical Sociology at the University of Leipzig, Germany. Her research interests are epidemiology, especially on traumatic experiences and related health outcomes, psychometrics, health services research and research on suicidality.

\section{Competing interests}

The author declares that she has no competing interests.

Received: 4 August 2015 Accepted: 27 May 2016

Published online: 14 June 2016

\section{References}

1. Gilbert R, Widom CS, Browne K, Fergusson D, Webb E, Janson S. Child Maltreatment 1 Burden and consequences of child maltreatment in highincome countries. Lancet. 2009;373:68-81. 
2. Norman RE, Byambaa M, De R, Butchart A, Scott J, Vos T. The longterm health consequences of child physical abuse, emotional abuse, and neglect: a systematic review and meta-analysis. Plos Med. 2012;9:e1001349.

3. Gilbert R, Kemp A, Thoburn J, Sidebotham P, Radford L, Glaser D, et al. Child maltreatment 2 recognising and responding to child maltreatment. Lancet. 2009:373:167-80.

4. Kessler RC, Davis CG, Kendler KS. Childhood adversity and adult psychiatric disorder in the US National Comorbidity Survey. Psychol Med. 1997;27:1101-19.

5. Shonkoff JP, Boyce W, McEwen BS. Neuroscience, molecular biology, and the childhood roots of health disparities building a new framework for health promotion and disease prevention. JAMA. 2009;301:2252-9.

6. Hovdestad W, Campeau A, Potter D, Tonmyr L. A systematic review of childhood maltreatment assessments in population-representative surveys since 1990. Plos ONE. 2015;10:e0123366.

7. Perkonigg A, Kessler RC, Storz S, Wittchen HU. Traumatic events and posttraumatic stress disorder in the community: prevalence, risk factors and comorbidity. Acta Psychiatr Scand. 2000;101:46-59.

8. Bernstein DP, Stein JA, Newcomb MD, Walker E, Pogge D, Ahluvalia T, et al. Development and validation of a brief screening version of the Childhood Trauma Questionnaire. Child Abuse Negl. 2003;27:169-90.

9. Baker AJ, Maiorino E. Assessments of emotional abuse and neglect with the CTQ: issues and estimates. Child Youth Serv Rev. 2010:32:740-8.

10. Walker EA, Gelfand A, Katon WJ, Koss MP, Von Korff M, Bernstein D, et al. Adult health status of women with histories of childhood abuse and neglect. Am J Med. 1999;107:332-9.

11. Gerdner A, Allgulander C. Psychometric properties of the Swedish version of the Childhood Trauma QuestionnaireShort Form (CTQ-SF). Nord J Psychiatry. 2009;63:160-70.

12. Grassi-Oliveira R, Cogo-Moreira H, Salum GA, Brietzke E, Viola TW, Manfro GG, et al. Childhood Trauma Questionnaire (CTQ) in Brazilian samples of different age groups: findings from confirmatory factor analysis. Plos ONE. 2014;9:e87118.

13. Klinitzke G, Romppel M, Hauser W, Brahler E, Glaesmer H. The German Version of the Childhood Trauma Questionnaire (CTQ) — psychometric characteristics in a representative sample of the general population. Psychother Psychosom Med Psychol. 2012;62:47-51.

14. Villano CL, Cleland C, Rosenblum A, Fong C, Nuttbrock L, Marthol M, et al. Psychometric utility of the Childhood Trauma Questionnaire with female street-based sex workers. J Trauma Dissociation. 2004;5:33-41.
15. Wingenfeld K, Spitzer C, Mensebach C, Grabe HJ, Hill A, Gast U, et al. The German Version of the Childhood Trauma Questionnaire (CTQ): preliminary psychometric properties. Psychother Psychosom Med Psychol. 2010;60:442-50.

16. Bernstein DP, Fink L, Handelsman L, Foote J, Lovejoy M, Wenzel K, et al. initial reliability and validity of a new retrospective measure of child-abuse and neglect. Am J Psychiatry. 1994;151:1132-6.

17. Bernstein DP, Ahluvalia T, Pogge D, Handelsman L. Validity of the Childhood Trauma Questionnaire in an adolescent psychiatric population. J Am Acad Child Adolesc Psychiatry. 1995;36:340-8.

18. MacDonald K, Thomas ML, MacDonald TM, Sciolla AF. A perfect childhood? Clinical correlates of minimization and denial on the Childhood Trauma Questionnaire. J Interpers Violence. 2014;30:988-1009.

19. MacDonald K, Thomas ML, Sciolla AF, Schneider B, Pappas K, Bleijenberg G, Bohus M, Bekh B, Carpenter L, Carr A, Dannlowski U, Dorahy M, Fahlke C, Finzi-Dottan R, Karu T, Gerdner A, Glaesmer H, Grabe HJ, Heins M, Kenny DT, Kim D, Knoop H, Lobbestael J, Lochner C, Lauritzen G, Ravndal E, Riggs S, Sar V, Schäfer I, Schlosser N, Schwandt ML, Stein MB, Subic-Wrana C, Vogel M, Wingenfeld K. Minimization of childhood maltreatment is common and consequential: results from a large, multinational sample using the childhood trauma questionnaire. PLOS ONE. 2016:11(1):e0146058.

20. Grabe HJ, Schulz A, Schmidt CO, Appel K, Driessen M, Wingenfeld K, et al. A brief instrument for the assessment of childhood abuse and neglect: the Childhood Trauma Screener (CTS). Psychiatr Prax. 2012;39:109-15.

21. Glaesmer H, Schulz A, Häuser W, Freyberger H, Braehler E, Grabe HJ. Der Childhood Trauma Screener (CTS)_Entwicklung und Validierung von Schwellenwerten zur Klassifikation. Psychiatr Prax. 2013;40:220.

22. Iffland B, Braehler E, Neuner F, Haeuser W, Glaesmer H. Frequency of child maltreatment in a representative sample of the German population. BMC Public Health. 2013;13:980.

23. Hauser W, Schmutzer G, Brahler E, Glaesmer H. Maltreatment in childhood and adolescence results from a survey of a representative sample of the German population. Deutsch Arztebl Int. 2011;108:287-2U5.

24. Hauffa R, Rief W, Brähler E, Martin A, Mewes R, Glaesmer H. Lifetime traumatic experiences and postraumtic stress disorder in the German population -results of a representative population sample. J Nerv Mental Dis. 2011;199:934-9.

25. Maercker A, Forstmeier S, Wagner B, Glaesmer H, Brahler E. Post-traumatic stress disorder in Germany. Results of a nationwide epidemiological study. Nervenarzt. 2008;79:577-86

\section{Submit your next manuscript to BioMed Central and we will help you at every step:}

- We accept pre-submission inquiries

- Our selector tool helps you to find the most relevant journal

- We provide round the clock customer support

- Convenient online submission

- Thorough peer review

- Inclusion in PubMed and all major indexing services

- Maximum visibility for your research

Submit your manuscript at www.biomedcentral com/submit
BioMed Central 